\title{
Article
}

\section{Fire Retardant Action of Layered Double Hydroxides and Zirconium Phosphate Nanocomposites Fillers in Polyisocyanurate Foams}

Asimakopoulou, Eleni, Zhang, Jianping, Mckee, Maurice, Wieczorek, Kinga, Krawczyk, Anna, Andolfo, Michele, Scatto, Marco, Sisani, Michele, Bastianini, Maria, Karakassides, Anastasios and Papakonstantinou, Pagona

Available at http://clok.uclan.ac.uk/31845/

Asimakopoulou, Eleni ORCID: 0000-0001-5644-1372, Zhang, Jianping, Mckee, Maurice, Wieczorek, Kinga, Krawczyk, Anna, Andolfo, Michele, Scatto, Marco, Sisani, Michele, Bastianini, Maria et al (2020) Fire Retardant Action of Layered Double Hydroxides and Zirconium Phosphate Nanocomposites Fillers in Polyisocyanurate Foams. Fire Technology . ISSN 0015-2684

It is advisable to refer to the publisher's version if you intend to cite from the work. http://dx.doi.org/10.1007/s10694-020-00953-7

For more information about UCLan's research in this area go to http://www.uclan.ac.uk/researchgroups/ and search for < name of research Group>.

For information about Research generally at UCLan please go to http://www.uclan.ac.uk/research/

All outputs in CLoK are protected by Intellectual Property Rights law, including Copyright law. Copyright, IPR and Moral Rights for the works on this site are retained by the individual authors and/or other copyright owners. Terms and conditions for use of this material are defined in the policies page. 


\title{
Fire retardant action of Layered Double Hydroxides and Zirconium Phosphate nanocomposites fillers in polyisocyanurate foams
}

\begin{abstract}
Modern day energy codes are driving the design and multi-layered configuration of exterior wall systems with a significant emphasis on achieving high performance insulation towards improving energy performance of building envelopes. Use of highly insulating polyisocyanurate (PIR) based materials enhanced with eco-friendly lamellar inorganic fillers reinforces energy performance requirements, environmental challenges and cost reduction without compromising the overall building fire safety. The current work assessed the fire behaviour of PIR modified with three layered fillers, namely MgAlCO3 (PIR-LDH1), MgAl Stearate (PIR-LDH2) and Zirconium Phosphate octadecylamine (PIR-ZrP3). For each of the fillers, three loadings ( 2,4 and $6 \%$ by weight) were used. Optical analysis by X-ray diffraction patterns (XRD), cone calorimeter (CC), thermogravimetric (TGA) analysis, post-burning morphological evaluation using field emission scanning electron microscope (FESEM) and diffuse reflectance infrared spectroscopy (DRIFT) analysis, were performed. The results indicated that fire reaction properties and thermal stability of foam samples were enhanced with three different types of lamellar inorganic smart fillers. The initial degradation temperature of PIR-layered filler samples was increased, demonstrating that incorporation of flame retardants decelerated the degradation of PIR foam and contributed to significant char formation, from $19.5 \%$ in pure PIR samples to $33 \%$ in PIR-6\%LDH1 samples. Increasing the filler content also resulted in improved char properties and decreased peak Heat Release Rates (HRR) in the cone calorimeter. Due to the development of a stable char layer, samples containing $6 \%$ of $\mathrm{ZrP} 3$ did not ignite at $20 \mathrm{~kW} / \mathrm{m}^{2}$ and a reduction of up to $40 \%$ in the peak HRR was achieved in PIR-2\%ZrP3 samples.
\end{abstract}

KEYWORDS: polyisocyanurate insulation; layered doubled hydroxides; zirconium phosphate; fire performance; fire retardant 


\section{INTRODUCTION}

There is an increasing need for improving the insulation properties of building envelopes driven by modern day energy codes for exterior wall systems. Increased insulation properties in multi-layer walls can be achieved with the use of non-combustible insulation materials, e.g. fiberglass and rockwool, and by using a wide range of highly insulating combustible foam materials. Most commonly used insulation materials include polymers such as extruded polystyrene (XPS), expanded polystyrene (EPS), polyurethane foam (PUF) and polyisocyanurate (PIR) with or without flame retardants [1]. In order to meet energy performance requirements, environmental challenges and cost reduction without undue compromise the overall building fire safety requires appropriate design of these materials.

The use of fillers in PIR foams can reinforce the polymer matrices in terms of energy performance, mechanical and thermal stability, smoke suppression and fire-retardant properties $[2,3,4,5]$. To improve the fire-retardant performance of polymer insulation-related flame retardants, there is a tendency to substitute the commonly used halogenated flame retardants with more eco-friendly "greener" ones. Following contemporary sustainability requirements, there is a tendency to substitute halogen flame retardants with eco-friendly greener ones. -In contrast to halogenated flame-retardants, Layered Double Hydroxides (LDHs) and Zirconium Phosphate ( $\mathrm{rP}$ ) nanocomposites are among the most promising halogen-free mineral nanostructurant fillers. LDH and ZrP can substantially reduce the release of corrosive and toxic volatile compounds from combustion $[6,7,8,9,10,11\}$. Both LDHs and $\mathrm{ZrP}$ are currently been explored as second-generation more environmentally friendly fire-retardant additives with reduced toxicity and physiological effects $[6,7,8,9,10,11]$ that could threaten human health since during burning they produce reduced amount of smoke [12, 13, 14] and no brominated dioxins as compare to widely used halogenated flame retardants [15]. Their increased fire retardancy is observed in both gas and solid phases as they develop non-flammable gases diluting flammable gases and promoting surface charring [16]. At elevated temperatures, LDHs and ZrP have been shown to release interlayer water, intercalated anions and hydroxyl groups, resulting in local cooling of the flaming material and endothermic decomposition [17, 18, 19].

Despite their effectiveness, LDHs and ZrP have until now limited commercial success as fire retardants because of difficulty in dispersing and distributing them in polymers, which limits their effectiveness [10]. Different authors have recently studied several types and contents of LDHs in polymeric-based insulation materials, mostly in PUF-[e.g., 10, 11\} and most of these studies concern their incerperation in PUF. A recent study [19] investigated the potential synergistic effect between organically modified nanoclay LDHs and flame retardants (expanded graphite and melamine polyphosphate) on rigid PUF (RPUF) for improving the fire retardancy and fire behaviour. LDHs demonstrated synergistic effects

Formatted: Font color: Blue

Formatted: Font color: Blue

Formatted: Font color: Blue

Formatted: Font color: Blue 
with intumescent flame retardants on improving fire behavior of RPUF by decreasing the initial decomposition temperature, the second stage-maximum-rate decomposition, the char residue at high temperatures and the, the heat release rate, the smoke release, and the $\mathrm{CO} / \mathrm{CO}_{2}$ ratio. Specifically, wWith 40 wt. \% of LDH loading, the peak Heat Release Rate (HRR) was reduced by up to 54\% [19]. Several authors employed-Cone Calorimeter (CC) has been widely used to determine flammability parameters in polymeric based insulation materials containing different types and percentages of LDHs to characterize several types and contents of $\mathrm{LDH}$ in pelymeric based insulation materials- $[10$, $20,21,22]$. In [10] the replacement of the most frequently used nanoparticle to enhance fire resistance montmorillonite clay (MMT) with LDH, resulted in a more effective fire-resistant coating. A reduction of the flammability was in the range of 20 to $40 \%$ for peak HRR and $50 \%$ to $80 \%$ for average HRR. This increased fire resistance and char formation was attributed to the additional pathways provided by LDH. It was observed that, LDH releases water which acts in the gas phase to dilute the fuel and goes through an endothermic decomposition of its metal hydroxide layers. This endothermic decomposition decreases the polymer temperature and slows down pyrolysis. Cone Calorimetry (CC) analysis has also been used to investigate the fire hazards of combustible closed-cell polymeric insulation materials, such as PIR, by determining flammability parameters, such as the critical temperature, which could be used in the frame of performance-based design [22].

These studies clearly highlighted the potential of using LDH er and $\mathrm{ZrP}$ in rigid forms for improved thermal stability and fire performance. The focus of the current work is thus to fill this knowledge gap.to extend existing work on PUR foams $[5.10,11]$ and further investigate fire retardant action of $\underline{\mathrm{LDH}}$ and $\mathrm{ZrP}$ in PIR foams. limited research on the incorporation of LDH and ZrP in PIR foams. Two representative $\mathrm{LDHs}, \mathrm{MgAlCO}_{3}$ (LDH1) and $\mathrm{MgAl}$ Stearate (LDH2) and one ZrP Zirconium Phosphate octadecylamine ( $\mathrm{ZrP} 3)$ were used. Furthermore, thethe effect of each filler's concentration was also varied $(2,4,6 \%$ by weight) to examines its effect on the thermal degradation and flammability of the PIR foam_was also investigated. The cellular structure and morphology of the virgin foams were first examined using XRD and field emission scanning electron microscope (FESEM) techniques. Subsequently, thermal stability and fire reaction properties of PIR samples incerporating three types of lamellar inorganic smart fillers were investigated using TGA and CC.TGA is used to determine how the fillers affect the degradation and thermal stability of the foam. whereas- $\mathrm{CC}$ is used to evaluates the overall fire performance of the composites in terms of heat release, ignition, mass loss and production of toxic gases such as CO and smoke. Finally, postburning morphological evaluation of the char residues of all formulations was performed using FESEM and diffuse reflectance infrared spectroscopy (DRIFT).
Formatted: Font color: Blue

Formatted: Font color: Blue

Formatted: Font color: Blue
Formatted: Font color: Blue
Formatted: Font color: Blue
Formatted: Font color: Blue
Formatted: Font color: Blue

Formatted: Font color: Blue 


\section{EXPERIMENTAL}

\subsection{Test methods}

Optical Microscopy at $500 \mu \mathrm{m}$ scale was used for the morphological evaluation of the foam structure of each filler and virgin foam sample. Cellular structure of the samples, both virgin and charred, and fillers was evaluated using a field emission scanning electron microscope (FESEM, Hitachi SU 5000) at an accelerating voltage of $15 \mathrm{kV}$, coupled with Energy Dispersive X-Ray (EDX) analysis (EDX probe Bruker), to provide elemental identification. The crystal structures of the samples were analyzed by X-ray diffraction patterns (XRD) with a Bruker D2 Phaser diffractometer operating at $30 \mathrm{kV}$ and $15 \mathrm{~mA}$, step size of $0.022 \theta$ degrees, and step time of $1 \mathrm{~s}$, employing a $\mathrm{Cu} \mathrm{K} \alpha$ radiation and multistrip LYNXEYE SSD160 detector.

Thermal stability was evaluated using thermogravimetric analysis (TGA) under $\mathrm{N}_{2}$ (inert gas) in a Mettler Toledo TGA apparatus. $10 \mathrm{mg}$ PIR foam sample was placed in an alumina pan with no lid [23]. The heating rate was $20^{\circ} \mathrm{C} / \mathrm{min}$ with a $\mathrm{N}_{2}$ flow of $150 \mathrm{ml} / \mathrm{min}$. The following parameters were determined: initial degradation temperature, temperature at $5 \%$ weight loss $\left(T_{5} \%\right)$, the weight, $W$, at the maximum weight loss rate and corresponding maximum temperature, $T_{\max }$, for each degradation step and char residue up to $1000^{\circ} \mathrm{C}$. Dual replicates were used to check the repeatability of the results.

Formatted: Font color: Blue Cone calorimeter (CC) tests were performed with a Dark Star Research Ltd (UK) apparatus according to the ISO 5660-1 [24]. The size of the sample for the cone calorimeter tests was $100 \mathrm{~mm} \times 100 \mathrm{~mm} x$ $24 \mathrm{~mm}$. The sample thickness $(24 \mathrm{~mm})$ was chosen based on a preliminary study using samples with different thickness $(6,12$ and 24mm). The samples were horizontally placed in a $106 \mathrm{~mm}$ x $106 \mathrm{mmx}$ $26 \mathrm{~mm}$ stainless steel metal holder with $2.4 \mathrm{~mm}$ thickness. At least two repeatability tests were performed for each specimen. The interior surface was insulated with 2 sheets of $3 \mathrm{~mm}$ thick high temperature vitreous wool Insulfrax ${ }^{\circledR}$ Paper, with a nominal density of $150 \mathrm{~kg} / \mathrm{m}^{3}$ and conductivity of $0.098 \mathrm{~W} / \mathrm{mK}$ at $400^{\circ} \mathrm{C}$, coated with $0.07 \mathrm{~mm}$ AT502 30 Micron aluminium foil tape, Category 1 according to BS476 Part 6 and 7 [25, 26]. All samples were conditioned before testing according to ISO 554 [27] at a temperature of $23^{\circ} \mathrm{C}+/-2^{\circ} \mathrm{C}$ and at a relative humidity of $50 \%+/-5 \%$. The exposed surface of the samples was carefully insulated before exposure in order to avoid preheating of the sample. Melting and dripping aspects were not investigated in the current work. Experimental results include time to ignition (TTI), Combustion Time (CT), total HRR (THR), peak HRR (p-HHR), average HRR (Av-HRR), average mass loss rate (Av-MLR), smoke production rate (SPR), smoke and CO yield. Additionally, temperature of the unexposed surface was measured using a $1 \mathrm{~mm}$ type K shielded thermocouple placed at the back of the specimen. Two digital cameras were positioned facing the front 
and side of the test apparatus to record observations regarding specimen burning and smoke colour. The uncertainty of the measurements complies to ISO 5660. The holder was adequate to support the edges of the samples in the initial burning stages and thus no additional retainer frame was used to prevent samples deformation. For several samples, significant glowing was observed after flameout. For both TGA and CC, dual replicates were used to check the repeatability of the results and since results were reproducible, the values presented in this work is the value for one of the tests.

Fourier transform diffuse reflectance infrared spectroscopy (DRIFT), was performed for charred samples [28] using a Bruker spectrometer in the range $400-4000 \mathrm{~cm}^{-1}$ with a resolution of $4 \mathrm{~cm}^{-1}$. The charred samples were collected from burnt samples after CC tests. $1.5 \mathrm{mg}$ from each charred sample was grounded with $300 \mathrm{mg}$ of $\mathrm{KBr}$ to form pellets. The scanner velocity was set to $10 \mathrm{~Hz}$ and 64 scans were used to obtain spectra with good signal-to-noise ratios. Samples were loaded into the DRIFT cups and their surface was levelled with a slide. The intensity of the infrared peaks was expressed in Kubelka-Munk units. Rubberband Correction method was used for the baseline correction and the data were normalized using the peak absorbance of each spectrum and then assigned to vibrations of certain functional groups, as commonly used for char characterisation [29].

\subsection{Samples preparation}

PIR foams are part of the polyurethane rigid foam family and their main characteristic is that they contain a high percentage of cyclic isocyanurate chemical linkages and use of polyester polyol instead of the standard polyether polyol used in polyurethanes.PIR samples with a constant isocyanate index $(\mathrm{NCO} / \mathrm{OH})$ of 3.0 were obtained from lab-scale prototyping experiments conducted at SELENA Labs. Samples were produced by high pressure impingement mixing type of foam machinery, operating at constant processing parameters. Initial premixing of the main components of the polyol blend including polyol, catalysts, stabilizer and methylal blowing agent, was performed for 2-3 min at 1500 rpm. This polyol mix was then mixed with fillers for $5 \mathrm{~min}$ at $2500 \mathrm{rpm}$. The required amounts of isocyanate, methylene diphenyl diisocyanate (MDI), were finally poured into the mixture and stirred for $10 \mathrm{~s}$ at a constant speed. Three new types of PIR foams samples with ecofriendly and soft chemical synthesis layered fillers with high purity metal salts (e.g. $\mathrm{Mg}$ and $\mathrm{Al}) \mathrm{MgAlCO}_{3}$ (LDH1), $\mathrm{MgAl}$ Stearate (LDH2) and Zirconium Phosphate octadecylamine (ZrP3) were tested. Tested mixtures will be referred to as PIR, PIR-MgAlCO 3 (PIR-LDH1), PIR-MgAl Stearate (PIR-LDH2), and Zirconium Phosphate PIR-ZrP octadecylamine (PIR-ZrP3). Research on $\mathrm{ZrP}, \mathrm{MgAlCO}_{3}, \mathrm{MgAl}$ and other types of $\mathrm{LDH}$ fillers revealed that their incorporation in polyurethane composites in a range of concentrations from $0.5 \%$ to $8 \%[3,4,10,11]$, improved their thermal properties [3], flame retardancy [4] resulting in decreased HRR [11]. Three concentrations of each filler in each of the samples were examined, i.e., 2, 
4 and $6 \%$ by weight. The density of the samples did not significantly change when the fillers are added as shown in Table 1. For simplicity, the three different samples of PIR-LDH1 will be referred to as PIR-2\%LDH1, PIR-4\%LDH1 and PIR-6\%LDH1 and similarly for the PIR-LDH2 and PIR-ZrP3 mixtures. In total, nine different FRs-containing formulations were prepared, investigated and assessed against pure PIR samples.

\subsection{Structural characterization of nanocomposite fillers}

LDH1, LDH2 and ZrP3 are organically modified layered nanocomposite fillers, in which organic modification acts alse-as a compatibilizer between the filler and polymer matrix. The origin of their increased flame retardancy and smoke suppression properties is derived from their unique chemical composition and layered structure [19]. The XRD pattern and surface morphologies at high magnification $(1 \mu \mathrm{m})$ of the plain fillers are depicted in Figure 1. Diffraction peaks and broad asymmetric peaks at high $2 \theta$ angles in the XRD patterns of LDH1 are indicative of features of materials with layered structure [30, 31]. Sharp symmetric peaks at low angles were observed for LDH1, LDH2 and $\mathrm{ZrP3}$, which correspond to the basal reflection and higher harmonics [31]. Existence of strong intensity of reflections suggests that all fillers have well developed layer structure with good crystallinity. In LDH1, XRD data indicate the presence of carbonate as a Bragg diffraction peak appears-at an angle of 11.6 degrees corresponding to d-spacing of $7.80 \AA$ of the MgAl-carbonate [32]. The SEMs images in [31] also show that the LHD fillers in their virgin form are highly crystalline and monodispersive $\{31\}$. LDH1 morphology has a typical polygonal shape formed plate-like particles as observed by other researchers [31]. In both LDH1 and LDH2 samples, platelets overlap with each other and form big particles, resulting from the significant aggregation of small LDH particles [31]. The microstructure of $\mathrm{ZrP} 3$ reveals a more irregular plate-like geometry and thewith a structure of ZxP3 isthat builtbuilt up by packing layers of bonded zirconium atoms [33]. Final reacting mixtures were poured centrally into a horizontal $35 \mathrm{~cm} \times 35 \mathrm{~cm}$ x $5 \mathrm{~cm}$ mold, heated at $60^{\circ} \mathrm{C}$, with steel facers attached to the bottom and the lid to complete the polymerization reaction.

\section{RESULTS AND DISCUSSION}

\subsection{Morphological evaluation of virgin materials}

A morphological evaluation, in terms of regular and cellular structure, of the tested samples was performed by optical microscopy at $500 \mu \mathrm{m}$, as depicted in Figure 2. The results show that varying the filler concentration does not significantly alter the morphology of the samples. The average cell diameter of PIR, PIR-6\% LDH1, PIR-6\% LDH2 and PU-6\% ZrP3 samples is $390 \mu \mathrm{m}, 312 \mu \mathrm{m}, 298$ $\mu \mathrm{m}$ and $242 \mu \mathrm{m}$ respectively. The cellular morphology of PIR with fillers has not been substantially 
changed in comparison to pure PIR samples and only PIR-6\% ZrP3 samples have a decreased average cell diameter.

Figure 3 shows the FESEM morphological evaluation of the above-mentioned samples along with the representative examples of respective EDX analysis in regions of the cell walls, which were used to verify the presence of the lamellar fillers in those regions. FESEM results showed that the addition of LDH fillers does not modify the cellular structure. There is no collapse or collision of the cellular structure and lamellar fillers are present in the walls of cells. All samples show a homogeneous cell structure and mainly closed cells indicating low water absorption, moisture permeability and thermal conductivity [42]. EDX data revealed the presence of $\mathrm{Mg}, \mathrm{Al}, \mathrm{C}, \mathrm{O}$ and $\mathrm{Cl}$ elements for PIR-2\%LDH1 and PIR-2\%LDH2 whereas $\mathrm{Zr}, \mathrm{C}, \mathrm{O}$ and $\mathrm{Cl}$ were identified in PIR-2\%ZrP3.

\subsection{Thermogravimetric analysis (TGA)}

Several studies [e.g., 2, 3, 4, 5, 34, 35] have established that thermal decomposition of polymeric foams is a complex process ansisting consists of numerous decomposition pathways that strongly depend on the reactivity of organic compounds employed in their synthesis. Studies [e.g., 36, 37] have shown that polyurethanes degradesdegrade in two or three steps and that the decomposition products are usually their precursor, such as isocyanate, amine, and hydroxyl compounds.

Figure 4 presents the weight loss and weight loss rate of the samples investigated. It can be observed that the degradation of all PIR foams in inert atmosphere occurs in several steps. Thermogravimetric analysis results related to the degradation of all the PIR samples are summarized in Table 1. The first pyrolysis step, taking place from $200^{\circ} \mathrm{C}$ to $400^{\circ} \mathrm{C}$, is identified as the main mass loss step [33]. The initial degradation temperature, $T_{5} \%$, is $255^{\circ} \mathrm{C}$ for pure PIR. Additional weight loss stage associated with water loss rising from physical absorbed water, crystal water and dehydroxylation of LDH1 and $\mathrm{LDH} 2$ have been observed for those samples between 130 and $240^{\circ} \mathrm{C}$ [4]. $\mathrm{ZrP} 3$ also undergoes a dehydration process with a maximum weight loss temperature at around $140^{\circ} \mathrm{C}$ [38]. At this stage weight loss is almost the same for all samples, corresponding to the amount of water present in the samples.

The presence of LDH1, LDH2 and ZrP3 fillers causes distinct changes in the thermal decomposition in comparison to pure PIR foam. It can be seen from Table 1 that $T_{5} \%_{-}$increases-compared with pure PIR foam, indicating that incorporation of flame retardants decelerates the degradation of PIR foam and as a result increases the thermal stability of PIR foam. Maximum degradation rate temperature, $T_{\max , 1}$, is however substantially decreased with the filler addition; and only in PIR-6\%ZrP3 remains approximately the same.

Formatted: Font color: Blue

Formatted: Font color: Blue 
This first step is related to the degradation of the urethane-urea linkages and polyol, releasing low calorific capacity products. $\mathrm{R}$; residue weight values of this first reaction are denoted as $W_{l}$. More specifically, this step is associated with the thermal degradation of the hard polyisocyanurate segment that is a depolycondensation process taking places at around $210^{\circ} \mathrm{C}$ [23]. In PIR-LDH1 and PIR-LDH2 samples of all concentrations, this step occurs earlier [31]. Even with the addition of only $2 \%$ of LDH2 and $\mathrm{ZrP3}$, this first decomposition stage is shifted to lower temperature ranges, the extent of weight loss decreases from $35.5 \%$ to about $22.5 \%$ to $25.8 \%$.

After the first polyisocyanurate decomposition stage, an additional weight loss is observed designated as Stage 2 in Table 1 for PIR-LDH1, PIR-LDH2 and PIR-ZrP3 samples of all concentrations. In PIRLDH1 and PIR-LDH2, this weight loss is associated with the decarbonization of the carbonate ions of the LDH1 that occur between $240^{\circ} \mathrm{C}$ and $460^{\circ} \mathrm{C}$ [31]. The weight loss between $409^{\circ} \mathrm{C}$ and $482{ }^{\circ} \mathrm{C}$ in the PIR-ZrP3 samples are associated with the release of absorbed amines to the phosphate platelets [39].

The third stage corresponds to the PIR decomposition and is associated with the degradation of polyol derived products with higher calorific capacity than those derived from isocyanate [11] and lower residue weight, $W_{3}$. This step associated with the degradation of the soft segment of the PIR foam, taking place between 400 and $600^{\circ} \mathrm{C}$. For pure PIR samples the maximum rate degradation temperature, $T_{\max , 3}$, is observed at $477^{\circ} \mathrm{C}$ with the final char residue of $19.5 \%$ of the initial mass. Comparatively, the residues of PIR-LDH1 and PIR-LDH2 are higher than those of pure PIR and PIR$\mathrm{ZrP} 3$ samples, indicating better thermal stability of those samples. This thermal stability is increased with an increasing filler content resulting in increased char formation.

\subsection{Cone Calorimeter (CC) analysis}

\subsection{Cone Calorimeter (CC) analysis}

In determining the optimal sample thickness for the cone calorimeter tests, tests were conducted for pure PIR samples with different sample thicknesses $(6,12$ and $24 \mathrm{~mm})$ and at different heat fluxes (20, 30,40 and $50 \mathrm{~kW} / \mathrm{m}^{2}$ ). Based on previous research results $[40,41]$ and the fact that this thickness more favorably corresponds to end-use products conditions, $24 \mathrm{~mm}$ samples were selected for testing.

Comparisens of the transient HRR and the unexpesed side temperature histeries are depicted in Figure 5 for samples with different thicknesses. The HRR curves for the $6 \mathrm{~mm}$ samples have one single peak and are closer to symmetrical one step curves [40] corresponding to thermally thin HRR curves [41]. With increasing sample thickness, HRR curves correspend to thermally thick conditions with an initiat peak prior to charring and one at the end of burning due to the heat reaching the back of the sample [41]. Based on these results and the fact that this thickness also more favorably corresponds to end-use
Formatted: Font color: Blue

Formatted: Font color: Blue 
products conditions, $24 \mathrm{~mm}$ samples were selected for the parametric evaluation of the effects of smart fillers on the burning behaviour of PIR.

Preliminary tests were conducted for $6 \%$ of $\mathrm{LDH} 1, \mathrm{LDH} 2$ and $\mathrm{ZrP} 3$ at four different heat fluxes, namely 20,30, 40 and $50 \mathrm{~kW} / \mathrm{m}^{2}$ and a comparison of the HRR histories is depicted in Figure $6 \underline{5}$. It can be observed that the trends of the HRR profiles are similar at different heat fluxes demonstrating that the fire retardancy of the fillers is consistent. Subsequently, all formulations were tested at one low heat flux, $20 \mathrm{~kW} / \mathrm{m}^{2}$, and one high heat flux, $50 \mathrm{~kW} / \mathrm{m}^{2}$, which approximately correspond to different fire scenarios, namely developing and fully developed fire respectively. Table 2 summarizes the flammability and smoke emission behaviour of all the samples. As shown in Table 2, almost all samples ignited instantly at $50 \mathrm{~kW} / \mathrm{m}^{2}$, whereas at $20 \mathrm{~kW} / \mathrm{m}^{2}$, some FRs-containing formulations didn't ignite indicating improved fire performance. Figures $7 \underline{6}$ and 8 -show comparisons of the HRR and smoke production rate (SPR)-histories. After ignitions, PIR foams started to char and a two-peak HRR curve was observed at both $20 \mathrm{~kW} / \mathrm{m}^{2}$ and $50 \mathrm{~kW} / \mathrm{m}^{2}$. The first p-HRR of neat PIR is highest among all formulations at both heat fluxes exceeding 150 and $250 \mathrm{~kW} / \mathrm{m}^{2}$ at 20 and $50 \mathrm{~kW} / \mathrm{m}^{2}$ respectively. The second p-HRR of neat PIR associated with the crack formation in the char layer and the fact that heat has reached the back of the sample is less intense. The water and carbon dioxide released dilute combustion gases and reduces endothermic decomposition of metal hydroxides absorbing substantial amounts of heat thus promoting the formation of an expanded carbonaceous coating or char on the polymer $[19,20]$. This latter inorganic-reinforced carbonaceous residue impedes the burning process by thermally protecting the bulk underlying polymer from being exposed to air, suppress smoke production due to suffocation [20] and slows down the combustion process [10, 12].

The presence of layered fillers contributed to a considerable decrease of the HRR and SPR, similar the ebservationsas also observed by Gomez-Fernandez et al. [11], demonstrating the beneficial effect of the addition of layered fillers for in fire performance. The decrease in the second peak of HRR is more pronounced, achieving a reduction of up to $40 \%$ of peak HRR for PIR-2\%ZrP3. PIR-4\%ZrP3 results in higher char residue, as the surface char layer reduced both the oxygen and heat fluxes towards the polymer surface thus limiting the volatile compounds [41]. These results are consistent with the previous findings that of the $\mathrm{LDH} 1, \mathrm{LDH} 2$ and $\mathrm{ZrP} 3$ fillers' capacity to reduce the of combustion rate [37] and flame retardancy properties of polymers [42, 43]. It can also be observed that both the It is observed that with ZrP3 fillers, THR and -peak HRR, dec-and SPR decrease with an increase in thedecreasing filler concentration. Under increased heat flux exposure, the maximum decrease in the p-HRR, 59\%, was achieved with PIR-2\% ZrP3 samples; also, $\mathrm{CO}$ and $\mathrm{CO}_{2}$ yields are significantly low. because the formation of a stronger char as shown in char residue analysis in the next section. It is important to note that even the addition of reduced amounts of LDH2 fillers in virgin polymeric

\begin{tabular}{l} 
Formatted: Font color: Blue \\
Formatted: Font color: Blue \\
\hline Formatted: Font color: Blue \\
\hline Formatted: Font color: Blue \\
\hline Formatted: Font color: Blue \\
\hline Formatted: Font color: Blue \\
\hline Formatted: Font color: Blue \\
\hline Formatted: Font color: Blue \\
\hline
\end{tabular}


materials can greatly affect their burning behaviour as both PIR-2\%LDH2 and PIR-4\%LDH2 did not achieve ignition at $20 \mathrm{~kW} / \mathrm{m}^{2}$. The great versatility in the behaviour of the PIR-LDH2 samples under lower heat exposure means that there must be an optimum concentration of LDH2 to be tuned with the structure of the PIR. Authors believe that this concentration could less than $6 \%$ it was resulted that PIR-2\%LDH2 and PIR-4\%LDH2 outperformed PIR-6\%LDH2 under all heat exposures. Among all the formulations, PIR-6\% ZrP3 has the best fire-performance as it did not ignite until $50 \mathrm{~kW} / \mathrm{m}^{2}$, as depicted in-Figure $6 \underline{5}$.

\subsection{Post-burning characterization and morphological evaluation of residual materials}

\subsection{Post-burning characterization and morphological evaluation of residual materials}

Figure 7 shows a comparison of the char residuals of all samples after the CC tests. There is considerable difference in the appearance depending upon the additives, especially at the higher heat flux, $50 \mathrm{~kW} / \mathrm{m}^{2}$, at which random deformation of the samples was observed, e.g., folding of the edges or rolling of the sample from the edges. An effective fire-retardant is the one that forms quickly, denser, thicker, and/or less cracked residues, and these qualities are indicative of good flame retardancy for a coated polymeric material [44]. As can be seen in Figure $\underline{7}$, the presence of fillers promotes the formation of a more rigid and hardened residual char layer. For pure PIR samples, Figure 7 (a) and (e), black smoke was observed during combustion and the residual char was brittle, with non-uniform distribution and its upper layer surface was detached and exfoliated. After exposure at lower heat flux, residual char from PIR-6\%LDH2, Figure 7 (c), and PIR-2\%LDH3, Figure 7 (d), had a very distinctive appearance which was intact and spongy; those samples did not ignite but substantial white smoke was observed. Under the lower heat flux level, the increased quality of the char layer formed in samples PIR-LDH2 and PIR-ZrP3 prevented the diffusion of volatiles and oxygen to the pyrolysis zone and averting the combustion front expanding in the whole depth of the samples, clearly demonstrating the improvement of their flame retardancy properties, in accordance with relevant literature for PUF samples with ZrP fillers [43]. Under higher heat fluxes, samples were deformed, Figure 7 (f) and (g), and in PIR-ZrP3, Figure 7 (h), several cracks were formed in the exposed char layer arising from the stresses produced by heating. It can also be noted in Table 2 that the smoke and $\mathrm{CO}$ yields from all filler-containing materials are similar to those of pure PIR, which is not surprising since these fillers mainly act in the solid phase [45]. This is further confirmed by the total heat released (THR) data as all samples have very close values at $50 \mathrm{~kW} / \mathrm{m}^{2}$. It is worth noting that THR values at $20 \mathrm{~kW} / \mathrm{m}^{2}$ are generally significantly less than that at $50 \mathrm{~kW} / \mathrm{m}^{2}$ indicating that the heat flux is too low to sustain the pyrolysis and burning of the polymer especially after the formation of the char layer. 
Figure 8 presents a comparison of the DRIFT spectra of the char residues of PIR, PIR-6\%LDH1, PIR-6\%LDH2 and PU-6\%ZrP3 after tests at $50 \mathrm{~kW} / \mathrm{m}^{2}$. Several distinct absorption peaks were found and the assignments for every band of the char spectra are shown in Table 3; associated data in [28], [29], [46], and [47] are also included for unburnt PIR samples. The peak separation and quantitative calculation were performed using Origin 8.0 and OPUS 7.2 (BRUKER) software. In all PIR char samples tested, the thermal degradation is associated with the dissociation of the urethane segment to primary and secondary amine, olefin and carbon dioxide (associated with the breakage of the bonds in the hard segment) [23]. Characteristic intense and wide peaks at $3200-3450 \mathrm{~cm}^{-1}, 2800-3000 \mathrm{~cm}^{-1}$ to $1050-1124 \mathrm{~cm}^{-1}$, observed for all charred samples, can be respectively associated with N-H stretching, aromatic C-H stretching and C-O stretching vibrations [28], [47]. The presence of carbonyl signal at $1724 \mathrm{~cm}^{-1}$ in PIR and PIR-6\%LDH1 spectrums illustrates the presence of urethane indicating that polyurethane was not completely degraded.

The morphology of the charred samples was determined using a field emission SEM for samples taken from the $\mathrm{CC}$ char residues after exposure at $50 \mathrm{~kW} / \mathrm{m}^{2}$. From the photos taken for the pure PIR sample, displayed in Figure9 (a)-(c), we can observe that an open cell polyhedral structure is dominant, with the cells being severely broken. In contrast, the PIR-6\%LDH1 sample, Figure 9 (d)(f), presents great difference in the cellular structure as the permeable nature of the sample, which is extremely loose, indicating it may not act adequately as a flame shield. The white amorphous regions that are scattered across the photograph are probably residual fillers. Increased porosity levels can be observed for PIR-6\%LDH2, Figure 9 (g)-(i), and the white amorphous regions are increased. In comparison with previous samples, a more compact and tight structure can be observed for PIR$6 \% \mathrm{ZrP} 3$, Figure_9 (j)-(1), with lower levels of porosity indicating it may act as a more adequate flame shield. This agrees with the finding in $[48,49]$ that $\alpha-\mathrm{ZrP}$ can lead to the formation of ceramiclike material with a homogeneous surface that can protect the main material throughout combustion and act towards formatting a mechanical reinforced charred layer.

\subsection{Overview of Flame retardancy of $L D H 1, L D H 2$ and $\mathrm{ZrP} \underline{3}$ additives in on PIR flame retardancy}

Figure 12 represents a graphical illustration of the flame retardancy of LDH1, LDH2 and ZrP3 additives in PIR as presented in previous sections. As it was revealed and In the condensed phase in accordance to research findings- $[3,4,10]$, char layer formation plays an important role in restraining the heat penetration and the intrusion of oxygen, thus protecting the underlying PIR matrix. As revealed

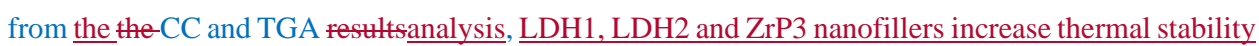
implying superior barrier properties $[50,51]$. The protective char layer formed in the presence of

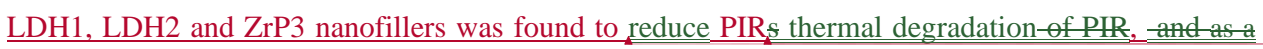

\begin{tabular}{l} 
Formatted: Font color: Blue \\
\hline Formatted: Font color: Blue \\
Formatted: Font color: Blue \\
Formatted: Font color: Blue
\end{tabular}

Formatted: Font color: Blue

Formatted: Font color: Blue

Formatted: Font color: Blue

Formatted: Font color: Blue 
result-decreases the heat release rate and the formation of toxic gases. $\mathrm{CC}$ and morphological analysis revealed that increased concentration of $\mathrm{ZrP3}$ resulted in more compact and tight char structures that could absorb greater amounts of energy and more efficiently shield the rest of the PIR. char layer reduces thermal degradation of PIR and decreases the heat release rate and the formation of toxic As depicted in Figure 12, LDH1, LDH2 and ZrP3 nanofillers act as barriers preventing pyrolysis gases to move towards the exposed to fire surface $[50,51]$. The decomposition ef the interealated anions and metal hydroxide produces water vapour and other gases, e.g. $\mathrm{CO}_{2}=\underline{\underline{T h i s}}$ ultimate fire retardancy is turning PIR into a protection-strong barrier char layer, especially in the case efPIR $6 \% \mathrm{ZrP3}$ as revealed by the morphologicalevaluation of the char samples, which absorbs energy and shields the rest of the PIR from radiation by reflecting heat.

The decomposition of the intercalated anions and metal hydroxide produces water vapour and other gases, e.g. $\mathrm{CO} 2-$ In the gas phase, aAs revealed by the TGA analysis, degradation of the urethane-urea and polyol of PIR results in the release of low calorific capacity products. In addition to that, during thermal decempesition, LDH1 and - LDH2 and ZrP3-fillers lose their intercalated anions and metal hydroxide thus producing water vapour and other gases, e.g. $\mathrm{CO}_{2}$ lose the interlayer water at 130 $24 \theta^{\ominus} \mathrm{C}$. ZrP3 fillers release the absorbed amines to the phosphate platelets. -Those released gases and water vapour act strongly in the gaseous phase in suppressing combustion will eventually reduce the availability of combustible fuel vapours-resulting in decreased HRR and promoting the formation of formatted-more condensed char structures [15].

\section{CONCLUSIONS}

\section{CONCLUSIONS}

\section{CONCLUSIONS}

\subsection{CONCLUSIONS}

This study evaluates the fire behaviour of PIR samples enhanced with lamellar inorganic fillers (PIR$\mathrm{MgAlCO}_{3}$ (PIR-LDH1), PIR-MgAl Stearate (PIR-LDH2), and Zirconium Phosphate PIR-ZrP octadecylamine (PIR-ZrP3), as well as their post-burning characterization and morphological evaluation of residual materials. The morphology and elemental analysis of the LDH fillers and PIR samples was conducted using FESEM, XRD and EDX. FESEM images of the LDH fillers in their virgin form revealed that they were highly crystalline and monodispersive. Morphological evaluation of the virgin samples showed a homogeneous cell structure and mainly closed cells indicating low water absorption, moisture permeability and thermal conductivity. EDX data of virgin samples

\section{Formatted: Font color: Blue}

Formatted: Font color: Blue

Formatted: Font color: Blue

Formatted: Font color: Blue

Formatted: Font color: Blue

Formatted: Font color: Blue, English (United Kingdom)

Formatted: Font color: Blue

Formatted: Font color: Blue

Formatted: Font color: Blue

Formatted: Font color: Blue 
revealed the presence of $\mathrm{Mg}, \mathrm{Al}, \mathrm{C}, \mathrm{O}$ and $\mathrm{Cl}$ elements for PIR-2\%LDH1 and PIR-2\%LDH2 whereas $\mathrm{Zr}, \mathrm{C}, \mathrm{O}$ and $\mathrm{Cl}$ were identified in PIR-2\% ZrP3.

TGA and CC analyses showed that layered fillers promoted the formation of a reinforced char layer, e.g. from $19.5 \%$ in pure PIR to $33 \%$ in PIR-6\%LDH1 in TGA, providing an effective barrier against heat and oxygen and release of noncombustible gases, whereas at the same time effectively suppressing smoke and gases during the combustion process. PIR-ZrP3 samples have the highest char residue and lowest p-HRR values. The CC results revealed that the use of different type of layered fillers do not lead to increased smoke or CO production. Increasing filler content resulted in augmented char formation for all samples and decreased p-HRR. Samples post-burning characterisation consistently suggested that fire resistance of PIR-ZrP3 samples was increased. At lower heat flux in CC analysis, PIR samples with fillers did not ignite and even in the case they did, PIR-2\%LDH2, PIR-2\%LDH2 and PIR-6\%ZrP3, combustion and smoke production were very limited. At the higher heat flux, the percentage of char residue was increased with an increase in the filler concentration, and emission of toxic substances was decreased as a more compact char was formed, as revealed from the post burning characterisation analysis from FESEM and DRIFT experiments. Based on the experimental measurements flame retardancy of LDH1, LDH2 and ZrP3 additives on PIR samples has been analysed.

Further analysis at different heating rates under both oxygen and inert atmospheres will be the focus of future work with a view of deriving a kinetic model to simulate the pyrolysis degradation mechanism of PIR-layered filler foams and oxidation of the char residue. Further assessment in terms of FTIRevolved gas analysis is currently planned in order to gain more information regarding the nature of the released gases under various heating conditions. Additional combination of different layered fillers and concentrations will be investigated in the future to further tune the fire resistance properties of PIR nanocomposites. The wealth of information provided can be used for further development and evaluation of thermal numerical models capable to accurately predict insulation materials behaviour under fire conditions that can be used in the frame of performance-based design. 


\section{REFERENCES}

[1] O’Connor D (2016) The Building Envelope: Fire Spread, Construction Features and Loss Examples, SFPE Handbook of Fire Protection Engineering ( $5^{\text {th }}$ ed) Hurley MJ, National Fire Protection Association, Quincy, MA 02269, 3242-3512.

[2] Asimakopoulou E, Zhang J, McKee M, Wieczorek K, Krawczyk A, Andolfo M, Scatto M, Michele S, Bastianini M (2018) Assessment of fire behaviour of polyisocyanurate (PIR) insulation foam enhanced with lamellar inorganic smart fillers, IOP Conf Series: Journal of Physics: Conf Series 1107: 032004, https://doi:10.1088/1742-6596/1107/3/032004

[3] Kotal M., Kuila T., Srivastava S.K., Bhowmick A.K. (2009) Synthesis and characterization of polyurethane/Mg-Al Layered Double Hydroxide nanocomposites, J Appl Polym Sci 114: 2691-2699, https://doi:10.1002/app.30791

[4] Starukh G., Budzinska, Brychka S.Ya. (2019) Structural characterization, thermal and mechanical properties of polyurethane-MgAl-layered double hydroxide nanocomposites prepared via physical dispersion, Applied Nanoscience 9:987-996, https://doi.org/10.1007/s13204-019-01035-z

[5] Kuranska M, Cabulis U, Auguscik M, Prociak A, Ryszkowaska J, Kirpluks M (2016) Bio-based polyurethane-polyisocyanurate composites with an intumescent flame retardant, Polym Degrad Stabil 127:11-19, http://dx.doi.org/10.1016/j.polymdegradstab.2016.02.005

[6] Kiliaris P, Papaspyrides CD (2010) Polymer/layered silicate (clay) nanocomposites: an overview of flame retardancy, Progr Polymer Science 35: 902-958, http://dx.doi.org/10.1016/j.progpolymsci. $\underline{2010.03 .001}$

[7] Gao L, Zheng G, Zhou Y, Feng G, Hu L, Feng G., Zhang M. (2014) Synergistic effect of expandable graphite, melamine polyphosphate and organically-modified layered double hydroxide on flame retardancy and fire behavior of polyisocyanurate-polyurethane foam nanocomposite, Polym Degrad Stabil 101: 92-101, http://dx.doi.org/10.1016/j.polymdegradstab.2013.12.025

[8] Hull TR, Witkowski A, Hollingbery L (2011) Fire retardant action of mineral fillers, Polym Degrad Stabil 96:1462-1469, http://dx.doi.org/10.1016/j.polymdegradstab.2011.05.006

[9] Edenharter A, Breu J (2015) Applying the flame retardant LDH as a Trojan horse for molecular flame retardants, Appl Clay Sci 114:603-608, http://dx.doi.org/10.1016/j.clay.2015.07.013

[10] Li YC, Yang YH, Shields JR, Davis RD (2015) Layered double hydroxide-based fire resistant coatings for flexible polyurethane foam, Polymer 56:284-292, http://dx.doi.org/10.1016 j.jpolymer.2014.11.0.23 
[11] Gomez-Fernandez S, Ugarte L, Pena-Rodriguez C, Zubitur M, Corceuera MA, Eceiza A (2016) Flexible polyurethane foam nanocomposites with modified layered hydroxides, Appl Clay Sci 123:109-120, https://doi.org/10.1016/j.clay.2016.01.015

[12] Wang DY (2016) Novel fire-retardant polymers and composite materials $\left(1^{\text {st }}\right.$ ed) Woodhead Publishing Series in Composite Science and Engineering, Woodhead Publishing.

[13] Nalawade P, Aware B, Kadam VJ, Hirlekar RS (2009) Layer double hydroxides: A review, J Sci Ind Res India 68:267-272

[14] Mills SJ, Christy AG, Genin JMR, Kameda T, Colombo F (2012) Nomenclature of the hydrotalcite supergroup: natural layered hydroxides, Mineral Mag 76:1289-1336,

https://doi.org/10.1180/minmag.2012.076.5.10

[15] Gao Y, Wu J, Wang Q, Wilkie C, O'Hare D (2014) Flame retardant polymer/layered double hydroxide nanocomposites, J Mater Chem A 2: 10996-11016, https://doi.org/10.1039/c4ta01030b

[16] Song L, Hu Y, Tang Y, Zhang R, Chen Z, Fan W (2005) Study on the properties of flame retardant polyurethane/organoclay nanocomposite, Polym Degrad Stabil 87:111-116,

https://doi.org/10.1016/j.polymdegradstab.2004.07.012

[17] Elbasuney S (2015) Surface engineering of layered double hydroxide (LDH) nanoparticles for polymer flame retardancy, Powder Technol 277: 63-73, https://doi.org/10.1016/j.powtec.2015.02.044

[18] Nyambo C, Kandare E, Wang D, Wilkie CA (2008) Flame-retarded polystyrene: Investigating chemical interactions between ammonium polyphosphate and $\mathrm{MgAl}$ layered double hydroxide, Polym Degrad Stabil 93: 1656-1663, https://doi.org/10.1016/j.polymdegradstab.2008.05.029

[19] Gao L., Zheng G., Zhou Y., Hu L., Feng G., Xie Y. (2013) Synergistic effect of expandable graphite, melamine polyphosphate and layered double hydroxide on improving the fire behavior of rosin-based rigid polyurethane foam, Ind Crop Prod 50: 638-647, http://dx.doi.org/10.1016/j.indcrop.2013.07.050

[20] Costa FR, Wagenknecht U, Heinrich G (2007) LDPE/Mg-Al layered double hydroxide nanocomposite: Thermal and flammability properties, Polym Degrad Stabil 92: 1813-1823, https://doi:10.1016/j.polymdegradstab.2007.07.009 
[21] Yang R, Hu W, Xu L, Song Y, Li J (2015) Synthesis, mechanical properties and fire behaviors of rigid polyurethane foam with reactive flame retardant containing phosphazene and phosphate, Polym Degrad Stabil 122:102-109, https://doi.org/10.1016/j.polymdegradstab.2015.10.007

[22] Hidalgo JP, Torero, JL, Welch S (2018) Experimental characterization of the fire behaviour of thermal insulation materials for a performance-based design methodology, Fire Technol 53: 12011232, https://doi.org/10.1007/s10694-016-0625-Z

[23] Chattopadhyay DK, Webster DC (2009) Thermal stability and flame retardancy of polyurethanes, Prog Polym Sci 34: 1068-1133, https://doi.org/10.1016/j.progpolymsci.2009.06.002

[24] ISO 5660-1 (2002) Reaction to fire tests - Heat release, smoke production and mass loss rate Part 1: Heat release rate (cone calorimeter method), International Organization for Standardization, Geneva, Switzerland.

[25] British Standards Institution (1989) 476-6: Fire tests on building materials and structures Method of test for fire propagation for products.

[26] British Standards Institution (1997) 476-7: Fire Tests on Building Materials and Structures Method of test to determine the classification of the surface spread of flame of products.

[27] ISO 554 (1974) Standard atmospheres for conditioning and/or testing specifications, International Organization for Standardization, Geneva, Switzerland.

[28] Sobkowiak M, Painter P (1995) A comparison of drift and KBr pellet methodologies for the quantitative analysis of functional groups in coal by infrared spectroscopy, Energy Fuels 9: 359-363, https://doi.org/10.1021/ef00050a022

[29] Odeh AO (2015) Qualitative and quantitative ATR-FTIR analysis and its application to coal char for different ranks, Journal of Fuel Chemistry and Technology 43(2):129-137, https://doi.org/10.1016/S1872-5813(15)30001-3

[30] Omonmhenle SI, Shannon IJ (2016) Synthesis and characterization of surfactant enhanced MgAL hydrotalcite-like compounds as potential 2-chlorophenol scavengers, Appl Clay Sci 127-128: 8894, https://doi.org/10.1016/j.clay.2016.03.033

[31] Peng Y, Wang W, Cao J, Guo X (2015) Effects of a layered double hydroxide (LDH) on the photostability of wood flour/polypropylene composites during UV weathering, RCS Advances 5: 41230-41237, https://doi.org/10.1039/c5ra04999g5 
[32] Nyambo C, Songtipya P, Manias E, Jimenez-Gasco M, Wilkie C (2018) Effect of MgAl-layered double hydroxide enhanced with linear alkyl carboxylates on fire-retardancy of PMMA and PS, J Mater Chem 18: 4827-4838, https://doi.org/10.1039/b806531d

[33] Jiang T, Liu C, Liu L, Hong J, Dong M, Deng X (2016) Synergistic flame retardant properties of a layered double hydroxide in combination with zirconium phosphonate in polypropylene, RCS Advances 6: 91720-91727, https://doi.org/10.1039/c6ra15542a

[34] Gunther M, Lorenzetti A, Schartel B (2018) Fire phenomena of rigid polyurethane foams, Polymers 10: 1-22, https://doi.org/10.3390/polym10101166

[35] Hidalgo JP, Torero JL, Welch S (2018) Fire performance of charring closed-cell polymeric insulation materials: Polyisocyanurate and phenolic foam, Fire Mater 42:358-373, http://dx.doi.org/10.1002/fam.2501

[36] Chen MJ, Wang X, Tao MC, Liu XY, Liu ZG, Zhang Y, Zhao CS, Wang JS, Full substitution of petroleum-based polyols by phosphorus-containing soy-based polyols for fabricating highly flameretardant polyisocyanurate foams, Polym Degrad Stabil 154 (2018) 312-322,

https://doi.org/10.1016/j.polymdegradstab.2018.07.001

[37] Liu X, Jianwei H, Gaan S (2016) Recent studies on the decomposition and strategies of smoke and toxicity suppression for polyurethane based materials, RSC Advances 6:72742-74756, http://dx.doi:10.1039/c6ra14345h

[38] Lu H, Wilkie CA (2011) The influence of a-zirconium phosphate on fire performance of EVA and PS composites, Polym Adv Technol 22: 1123-1130, http://dx.doi.org/10.1002/pat.1923

[39] Mendes LC, Silva DF, Araujo LJF, Lino AS (2014) Zirconium phosphate organically intercalated/exfoliated with long chain amine, J Therm Anal Calorim 118: 1461-1469,

http://dx.doi.org/10.1007/s10973-014-4056-0

[40] Lindholm J, Brink A, Hupa M (2012) Influence of decreased sample size on cone calorimeter results, Fire Mater 36: 63-73, http://dx.doi.org/10.1002/fam.1087 Cleary TG, Quintiere JG (1991) Flammability Characterization of Foam Plastics, NIST report NISTIR 4664: Gaithersburg, MD.

[41] Schartel B, Hull TR (2007) Development of fire-retarder materials - Interpretation of cone calorimeter data, Fire Mater 31: 327-354. https://doi.org/10.1002/fam.949

[42] Alongi J, Franche A (2010) Flame retardancy properties of a-zirconium phosphate-based composites, Polym Degrad Stabil 95:1928-1933, https://doi.org/10.1016/j.polymdegradstab.2010.04.007 
[43] Wang DY, Liu XQ, Wang JS, Wang YZ, Stec AA, Hull TR (2009) Preparation and characterization of a novel fire retardant PET/a-zirconium phosphate nanocomposite, Polym Degrad Stabil 94: 544-549, https://doi.org/10.4028/www.scientific.net/MSF.848.82

[44] Zhang X, Shen Q, Zhang X, Pan H, Lu Y (2016) Graphene oxide-filled multilayer coating to improve flame-retardant and smoke suppression properties of flexible polyurethane foam, J Mater Sci 51:10361-10374, https://doi.org/10.1007/s10853-016-0247-3

[45] Modesti M, Lorenetti A, Simioni F, Checchin M (2001) Influence of different flame retardants on fire behaviour of modified PIR/PUR polymers, Polym Degrad Stabil 74: 475-479,

https://doi.org/10.1016/S0141-3910(01)00171-9

[46] Zhao C, Yan Y, Hu Z, Li L, Fan X (2015) Preparation and characterization of granular silica aerogel/polyisocyanurate rigid foam composites, Constr Build Mater 93: 309-316, https://doi.org/10.1016/j.conbuildmat.2015.05.129

[47] Xu Q, Hong T, Zhou Z, Gao J, Xue L (2017) The effect of the trimerization catalyst on the thermal stability and the fire performance of the polyisocyanurate-polyurethane foam, Fire Mater 42 : 119-127, https://doi.org/10.1002/fam.2463

[48] Yang DD, Hu Y, Xu HP, Zhu LP (2013) Catalyzing carbonization of organophilic alphazirconium phosphate/acrylonitrile-butadiene-styrene copolymer nanocomposites, J Appl Polym Sci 130: 3038-3042, https://doi.org/10.1002/app.39224

[49] Wang D, Zhang Q, Zhou K, Yang W, Hu Y, Gong X (2014) The influence of manganese-cobalt oxide/graphene on reducing fire hazards of poly(butylene terephthalate), J Hazard Mater 278: 391400, http://dx.doi.org/10.1016/j.jhazmat.2014.05.072

[50] Yuan H, Qian X, Song L, Lu H (2014) Polymer/Layered compound nanocomposites: a way to improve fire safety of polymeric materials, Fire Safety Science 11:66-82,

https://doi.org/10.3801/IAFSS.FSS.11-66

[51] Yuan L, Yanashan G, Qiang W, Weiran L (2018) The synergistic effect of layered double hydroxides with other flame retardant additives for polymer nanocomposites: a critical review, Dalton Trans 47: 14827-14840, https://doi.org/10.1039/c8dt02949k 


\section{NOMENCLATURE}

\begin{tabular}{ll}
\hline Symbol & Units $\quad$ Description \\
\hline$T_{5 \%}$ & $\left({ }^{\circ} \mathrm{C}\right) \quad$ Temperature at 5\% weight loss \\
$T_{\max }$ & $\left({ }^{\circ} \mathrm{C}\right) \quad$ Temperature at maximum weight loss \\
$W$ & $(\mathrm{mg}) \quad$ Weight \\
\hline Acronyms & \\
\hline CC & Cone calorimeter \\
CT & Combustion time \\
DRIFT & Diffuse reflectance infrared spectroscopy \\
EDX & Energy dispersive X-ray \\
FESEM & Field emission scanning electron microscope \\
HRR & Heat release rate \\
LDHs & Layer Double Hydroxides \\
MDI & Methylene diphenyl diisocyanate \\
MLR & Mass loss rate \\
MMT & Montmorillonite clay \\
NCO/OH & Isocyanate index \\
PIR & Polyisocyanurate \\
PUF & Polyurethane foam \\
TGA & Thermogravimetric \\
THR & Total heat release \\
RPUF & Rigid PUF \\
SPR & Smoke production rate \\
THR & Total heat release \\
TTI & Time to ignition \\
XRD & X-ray diffraction \\
\hline &
\end{tabular}

\begin{tabular}{|c|}
\hline Formatted: Space Before: Auto, After: Auto \\
\hline Formatted: Space Before: Auto, After: Auto \\
\hline Formatted: Space Before: Auto, After: Auto \\
\hline Formatted: Space Before: Auto, After: Auto \\
\hline Formatted: Space Before: Auto, After: Auto \\
\hline Formatted: Space Before: Auto, After: Auto \\
\hline Formatted: Space Before: Auto, After: Auto \\
\hline Formatted: Space Before: Auto, After: Auto \\
\hline Formatted: Space Before: Auto, After: Auto \\
\hline Formatted: Space Before: Auto, After: Auto \\
\hline Formatted: Space Before: Auto, After: Auto \\
\hline Formatted: Space Before: Auto, After: Auto \\
\hline Formatted: Space Before: Auto, After: Auto \\
\hline Formatted: Space Before: Auto, After: Auto \\
\hline Formatted: Space Before: Auto, After: Auto \\
\hline Formatted: Space Before: Auto, After: Auto \\
\hline Formatted: Space Before: Auto, After: Auto \\
\hline Formatted: Space Before: Auto, After: Auto \\
\hline Formatted: Space Before: Auto, After: Auto \\
\hline Formatted: Space Before: Auto, After: Auto \\
\hline Formatted: Space Before: Auto, After: Auto \\
\hline Formatted: Space Before: Auto, After: Auto \\
\hline Formatted: Space Before: Auto, After: Auto \\
\hline Formatted: Space Before: Auto, After: Auto \\
\hline Formatted: Space Before: Auto, After: Auto \\
\hline
\end{tabular}




\section{FIGURE CAPTIONS}

Figure 1: FESEM morphological evaluation (white scale bar indicates $1 \mu \mathrm{m}$ ) of neat fillers (left) and their XRD spectra (right) of LDH1 (a), LDH2 (b) and ZrP3 (c).

Figure 2: Morphological evaluation (black scale bar indicates $500 \mu \mathrm{m}$ ) pure PIR (a), PIR-LDH1 (b), PIR-LDH2 (c) and PU-ZrP3 (d).

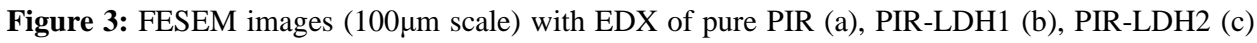
and PU-ZrP3 (d).

Figure 4: TG (left) and DTG (right) of pure PIR, PIR-LDH1, PIR-LDH2 and PIR-ZrP3 in $\mathrm{N}_{2}$ atmosphere.

Figure 5: Heat release rates of pure PIR, PIR-6\%LDH1, PIR-6\%LDH2 and PU-6\%ZrP3 at different heat fluxes.

Figure 6: Heat release rates of pure PIR, PIR-LDH1, PIR-LDH2 and PU-ZrP3 for $20 \mathrm{~kW} / \mathrm{m}^{2}$ (top) and $50 \mathrm{~kW} / \mathrm{m}^{2}$ (bottom).

Figure 8: Smoke production rates of pure PIR, PIR LDH1, PIR LDH2 and PU ZrP3 for $20 \mathrm{~kW} / \mathrm{m}^{2}$ (left) and $50 \mathrm{~kW} / \mathrm{m}^{2}$ (right).

Figure 7: Residual char digital photos of (a) and (e) PIR, (b) and (f) PIR-6\%LDH1, (c) and (g) PIR-6\%LDH2, (d) and (h) PIR-6\%ZrP3 charred samples after the CC testing at $20 \mathrm{~kW} / \mathrm{m} 2$, (a)-(d), and $50 \mathrm{~kW} / \mathrm{m} 2$, (e)-(h). 
Figure 8. Comparison of the DRIFT spectra of PIR, PIR-6\%LDH1, PIR-6\%LDH2 and PU-6\%ZrP3 char samples.

Figure 9. FESEM images of (a)-(c) PIR, (d)-(f) PIR-6\%LDH1, (g)-(i) PIR-6\%LDH2 and (j)-(l) PIR$6 \% \mathrm{ZrP} 3$ charred samples (black scale bar indicates $500 \mu \mathrm{m}$ and white $1 \mu \mathrm{m}$ ).

Figure 12. Diagrammatic illustration of the flame-retardancy of LDH1, LDH2 and ZrP3 in PIR. 


\section{TABLES CAPTIONS}

Table 1. TGA data of pure PIR, PIR-LDH1, PIR-LDH2 and PIR-ZrP3.

Table 2. Flammability and smoke emission behavior of pure PIR, PIR-LDH1, PIR-LDH2 and PIRZrP3 samples.

Table 3. DRIFT band assignment to functional groups. 